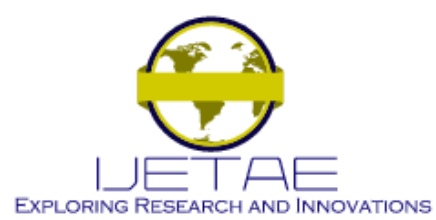

International Journal of Emerging Technology and Advanced Engineering

Website: www.ijetae.com (ISSN 2250-2459, ISO 9001:2008 Certified Journal, Volume 10, Issue 10, October 2020)

\title{
Game Model of Retailers Leading Closed-Loop Supply Chain under Different Guarantee Modes
}

Mei-xiang $\mathrm{Wu}^{1}$, Cheng-dong $\mathrm{Shi}^{2}$, Qiang $\mathrm{Sun}^{3}$

\begin{abstract}
In order to study the retailer-led differentiated guarantee behavior of CLSC's remanufactured products, assuming that demand is influenced by differentiated guarantee period of remanufactured products and consumers' willingness to pay, three game models of unguaranteed, manufacturer's guarantee and retailer's guarantee are constructed respectively to discuss the influence of guarantee mode selection and guarantee cost parameters on each member's decision. The results show that differentiated guarantees for remanufactured products are beneficial to extending the guarantee period, reducing the price of remanufactured products, improving CLSC members and overall profits. When consumers are less sensitive to differentiated guarantee for remanufactured products, CLSC decision in each mode has little to do with guarantee cost parameters and guarantor selection. When consumers are more sensitive, the advantages of each guarantee mode are significantly different, and manufacturer guarantee is the common choice of both parties. Finally, an example is given to further verify the conclusion.
\end{abstract}

keywords-Differentiated guarantee period for remanufactured product; Guarantee mode; Guarantee cost coefficient; Closed loop supply chain

\section{INTRODUCTION}

The urgency of conserving resources and protecting the environment has made countries all over the world pay more and more attention to sustainable development and circular economy. As an ideal model for waste product recycling, remanufactures can achieve more profit, drop cost and save energy of remanufacturing products [1]. It significantly reduces the adverse impact on the environment and has significant economic benefits and good environmental ecological benefits. Therefore, remanufacturing is an effective way to build a green model of energy saving, environmental protection and sustainable industry and develop circular economy. At present, the Chinese government has issued a series of supporting policies, such as "replacing old vehicles with new ones", extended production responsibility system, and management measures for the recovery of scrapped motor vehicles. Many manufacturing enterprises have joined in. However, in reality, consumers' cognition of the quality of remanufactured products is insufficient or high uncertainty, low willingness to pay is still unresolved.
Remanufactured product quality guarantee is a signal mechanism for remanufacturing enterprises to convey product quality to consumers, which can establish consumers' confidence in the quality of remanufactured products. A longer warranty period is generally considered to be an indication of better quality in remanufactured product [2]. Differentiated guarantee behavior of remanufactured products can improve consumers' trust in remanufactured products and stimulate consumers' willingness to pay by formulating appropriate guarantee period of remanufactured products. Therefore, how to balance the influence of factors such as differences in consumers' willingness to pay, guarantee cost coefficient, product substitution coefficient, guarantee period and selling price, and realize profit maximization is an important issue to be considered in guarantee service design.

\section{LiterATURE REVIEW}

Up to now, guarantee service of rework in closed-loop supply chain, and conducted modeling researches are analyzed from the following four perspectives:

a) Guarantee has the function of transmitting quality information and enhancing consumers' willingness to pay, such as Galor [3], Decroix [4], Balachander [5], Spence [6], Shimp and William [7],Tan [8] and Liao [9].

b) Manufacturers ' optimization decision and coordination of supply chain are taken into account such as guarantee period, product substitutable, guarantee level, recovery pricing, market randomness, and remanufacturing level, such as Li [10], Motlag [11], Liao[12-13], Li[14], Yazdian [15] and Alqahtan [16].

c) The choice of guarantee mode for remanufactured products under different circumstances, such as the difference of guarantor [17], the difference of guarantee measures whether to purchase trademark license [18].

Besides, literature [15] studies the manufacture-led retailer equity concern behavior of CLSC. [17] studied the strategic choice of whether to purchase trademark license and whether to remanufacture guarantee comparing the two guarantee methods of free replacement and extension of guarantee. 


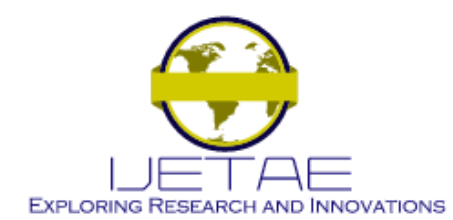

\section{International Journal of Emerging Technology and Advanced Engineering Website: www.ijetae.com (ISSN 2250-2459, ISO 9001:2008 Certified Journal, Volume 10, Issue 10, October 2020)}

Taking retailer-led closed-loop supply chain as research object, this paper analyzes the influence of guarantee party selection and guarantee level difference on decisionmaking, operation efficiency and member income of closed-loop supply chain.

\section{PRoblem DESCRIPTION AND BASIC Assumptions}

\section{A. Problem description}

In reality, consumers cannot directly evaluate product quality and generally believe that the quality of remanufactured products is lower than that of new products.

In order to develop retailer-led differentiated guarantee service and promotion scheme for remanufactured products of CLSC, this paper takes closed-loop supply chain composed of single retailer and manufacturer as research object, discusses the influence of differentiated guarantee behavior of CLSC upstream and downstream enterprise members on decision-making of closed-loop supply chain. For the convenience of description, manufacturers, retailers and supply chains as objects in the following paragraphs are replaced by $\mathrm{M}, \mathrm{R}$ and $\mathrm{SC}$ respectively.

\section{B. Definition of parameters}

$j=N F, M F, R F$ respectively represent the unsecured, manufacturer's guaranteed and retailer's guaranteed modes

$n, r$ represents new and remanufactured products

$m_{\mathrm{n}}^{\mathrm{j}}, m_{r}^{\mathrm{j}}, w_{n}^{\mathrm{j}}, w_{n}^{\mathrm{j}}, p_{n}^{\mathrm{j}}, p_{r}^{\mathrm{j}}, q_{n}^{\mathrm{j}}, q_{r}^{\mathrm{j}}$ respectively represent retailer's unit profit, wholesale price, selling price and sales volume under Mode $\mathrm{j}$ of new product and remanufactured product

$\pi_{m}^{\mathrm{j}}, \pi_{r}^{\mathrm{j}}, \pi_{s c}^{\mathrm{j}}$ represents the overall profit of $\mathrm{M}, \mathrm{R}$ and SC

\section{C. model assumptions}

a) Retailer is responsible for sales of new products and remanufactured products for leading party, while manufacturer is responsible for production of new products and recycling of remanufactured products for the following party. It is assumed that waste products recovered can meet the production demand of remanufacturing.

b) Because consumers cannot directly evaluate the product quality and generally believe that the quality of remanufactured product is lower than the quality of new product in order to eliminate consumers' concerns about the quality risk of remanufactured product, supply chain members provide differentiated guarantee service period $\mathrm{T}$, in which the guarantor is manufacturer or retailer. c) It is assumed that the guarantee cost under different guarantee modes is $0.5 \alpha_{i} t^{2}, i=m, r$ represents $\mathrm{MF}$ and $\mathrm{RF}$ modes. The guarantee period of new product and remanufactured product is 0 and $t$ respectively. Since the retailer is the dominant party, it is assumed that $\alpha_{r}<\alpha_{m}$.

d) It is assumed that two parties make rational decisions, information is symmetric, new and remanufactured products have the same function, but consumers' willingness to pay is different, respectively is $v$ and $\delta v$, where $\delta \in[0,1)$ denotes the degree of substitution of the remanufactured product for the new product. To ensure the profitability of remanufacturing activities, assume $\delta c_{n}>c_{r}$

e) It is assumed that consumer utility is $u_{n}=v-p_{n}, \quad u_{r}=\delta v-p_{r}+\beta \mathrm{t}$ where $\beta>0$ represents the effect of differentiated guarantee on the purchase utility of a remanufactured product. If $u_{n}>u_{r}$, $q_{n}=1-\frac{p_{n}-p_{r}+\beta \mathrm{t}}{1-\delta}, q_{r}=\frac{\delta p_{n}-p_{r}+\beta \mathrm{t}}{\delta(1-\delta)}$.

IV. Analysis On The Differentiated Guatantee Model Of Remanufactured Ptoductured Products IN RETAILER-LED CLSC

\section{A. Decision model in unsecured mode(NF)}

$$
\begin{aligned}
& \pi_{m}^{N F}\left(w_{n}, w_{r}\right)=\left(w_{n}-c_{n}\right) q_{n}+\left(w_{r}-c_{r}\right) q_{r} \\
& \pi_{r}^{N F}\left(p_{n}, p_{r}\right)=\left(p_{n}-w_{n}\right) q_{n}+\left(p_{r}-w_{r}\right) q_{r}
\end{aligned}
$$

By backward induction, the model has a unique optimal solution. It can be obtained by solving the model:

$$
\begin{aligned}
m_{n}^{N F} & =\frac{1-c_{n}}{2}, m_{r}^{N F}=\frac{\delta-c_{r}}{2}, w_{n}^{N F}=\frac{1+3 c_{n}}{4}, w_{r}^{N F}=\frac{\delta+3 c_{r}}{4} \\
p_{n}^{N F} & =\frac{3+c_{n}}{4}, p_{r}^{N F}=\frac{3 \delta+c_{r}}{4}, q_{n}^{N F}=\frac{1-\delta-c_{n}+c_{r}}{4(1-\delta)}, q_{r}^{N F}=\frac{\delta c_{n}-c_{r}}{4 \delta(1-\delta)} \\
\pi_{m}^{N R} & =\frac{\delta(1-\delta)+\delta c_{n}^{2}-2 \delta c_{n}\left(1-\delta+c_{r}\right)+c_{r}^{2}}{16(1-\delta) \delta}, \\
\pi_{r}^{N R} & =\frac{\delta-\delta^{2}+\delta c_{n}^{2}+2 \delta c_{n}\left(-1+\delta-c_{r}\right)+c_{r}^{2}}{8 \delta(1-\delta)}, \\
\pi_{s c}^{N R} & =\frac{3\left(\delta-\delta^{2}+\delta c_{n}^{2}+2 \delta c_{n}\left(-1+\delta-c_{r}\right)+c_{r}^{2}\right)}{16 \delta(1-\delta)}
\end{aligned}
$$

B. Decision model under manufacturer guarantee mode $(\mathrm{MF})$

$$
\begin{aligned}
& \pi_{m}^{M F}\left(w_{n}, w_{r}, t\right)=\left(w_{n}-c_{n}\right) q_{n}+\left(w_{r}-c_{r}\right) q_{r}-0.5 \alpha_{m} \mathrm{t}^{2} \\
& \pi_{r}^{M F}\left(p_{n}, p_{r}\right)=\left(p_{n}-w_{n}\right) q_{n}+\left(p_{r}-w_{r}\right) q_{r}
\end{aligned}
$$

By backward induction, the model has a unique optimal solution when $2 \delta \alpha_{m}(1-\delta)-\beta^{2}>0$. It can be obtained by solving the model: 


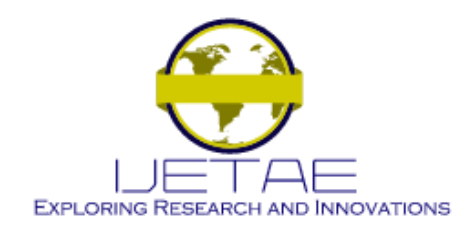

International Journal of Emerging Technology and Advanced Engineering Website: www.ijetae.com (ISSN 2250-2459, ISO 9001:2008 Certified Journal, Volume 10, Issue 10, October 2020)

$$
\begin{aligned}
& m_{n}^{M F}=\frac{1-c_{n}}{2}, m_{r}^{M F}=\frac{\delta-c_{r}}{2}, t^{M F}=\frac{\beta\left(\delta c_{n}-c_{r}\right)}{2\left(2 \delta \alpha_{m}(1-\delta)-\beta^{2}\right)} \\
& w_{n}^{M F}=\frac{1+3 c_{n}}{4}, w_{r}^{M F}=c_{r}+\frac{\delta\left(1-c_{n}\right)}{4}+\frac{\delta \alpha_{m}(1-\delta)\left(\delta c_{n}-c_{r}\right)}{2\left(2 \delta \alpha_{m}(1-\delta)-\beta^{2}\right)} \\
& p_{n}^{M F}=\frac{3+c_{n}}{4}, p_{r}^{M F}=\frac{c_{r}}{2}+\frac{\left(3-c_{n}\right) \delta}{4}+\frac{\delta \alpha_{m}(1-\delta)\left(\delta c_{n}-c_{r}\right)}{2\left(2 \delta \alpha_{m}(1-\delta)-\beta^{2}\right)} \\
& q_{n}^{M F}=\frac{1-c_{n}}{4}-\frac{\left(\delta c_{n}-c_{r}\right) \delta \alpha_{m}}{2\left(2 \delta \alpha_{m}(1-\delta)-\beta^{2}\right)}, \quad q_{r}^{M F}=\frac{\left(\delta c_{n}-c_{r}\right) \alpha_{m}}{2\left(2 \delta \alpha_{m}(1-\delta)-\beta^{2}\right)} \\
& \pi_{\mathrm{m}}^{M F}=\frac{\left(1-c_{n}\right)^{2}}{16}+\frac{\left(\delta c_{n}-c_{r}\right)^{2} \alpha_{m}}{8\left(2 \delta \alpha_{m}(1-\delta)-\beta^{2}\right)}, \\
& \pi_{r}^{M F}=\frac{\left(1-c_{n}\right)^{2}}{8}+\frac{\left(\delta c_{n}-c_{r}\right)^{2} \alpha_{m}}{4\left(2 \delta \alpha_{m}(1-\delta)-\beta^{2}\right)}, \\
& \pi_{s c}^{M F}=\frac{3\left(1-c_{n}\right)^{2}}{16}+\frac{3\left(\delta c_{n}-c_{r}\right)^{2} \alpha_{m}}{8\left(2 \delta \alpha_{m}(1-\delta)-\beta^{2}\right)}
\end{aligned}
$$

\section{Proposition 1:}

When $\alpha_{m}$ is greater than $\beta^{2} / 2 \delta(1-\delta)$, then $t^{M F}$ is greater than zero; When $\alpha_{m}$ is less than $\beta^{2} / 2 \delta(1-\delta)$, then $t^{M F}$ is less than zero; And $\partial \mathrm{t}^{M F} / \partial \alpha_{m}$ is less than zero.

Proof:

$$
\begin{aligned}
& \delta c_{n}>c_{r} \text {, the proposition } 1 \text { can be obtained from } \\
& t^{M F}=\frac{\beta\left(\delta c_{n}-c_{r}\right)}{2\left(2 \delta \alpha_{m}(1-\delta)-\beta^{2}\right)} \cdot \\
& \frac{\mathrm{t}^{M F}}{\partial \alpha_{m}}=-\frac{\beta(1-\delta) \delta\left(\delta c_{n}-c_{r}\right)}{2\left(2(1-\delta) \delta \alpha_{m}-\beta^{2}\right)^{2}}<0, \frac{\mathrm{t}^{M F}}{\partial \alpha_{m}}<0 \text { can be obtained. }
\end{aligned}
$$

When manufacturer undertakes the guarantee service, if differentiated guarantee cost of the remanufactured product is low, the manufacturer will actively propose the differentiated service of extending the guarantee period for remanufactured product to stimulate market, and the longer guarantee period can stimulate the consumer's willingness to pay, thus increasing sales of remanufactured product. At this point, although rework sales will eat into part of new product market, but manufacturer's total profit is increased. On the contrary, when differentiated guarantee cost of remanufactured goods is high, the increased willingness of consumers to pay and the increased remanufactured goods sales cannot recover manufacturer's cost of remanufactured goods, that is, the extended guarantee period of remanufactured goods cannot increase its profits. In this case, manufacturer will not provide differentiated guarantee service for remanufactured goods. In reality, the guarantee period of remanufactured products is generally shorter than or equal to new product, because consumers have a low willingness to pay for differentiated guarantee period, and remanufactured products eat into new product market or consider the guarantee cost.
In a word, the length of differentiated guarantee period of remanufactured products is negatively correlated with the guarantee parameters of remanufactured products.

Proposition 2:

$$
\begin{aligned}
& m_{n}^{M F}, m_{r}^{M F}, w_{n}^{M F} p_{n}^{M F} \text { has nothing to do with } \alpha_{m} \\
& \quad w_{r}^{M F}, p_{r}^{M F} q_{n}^{M F}, q_{r}^{M F}, \pi_{\mathrm{m}}^{M F}, \pi_{r}^{M F}, \mathrm{t}^{M F} \text { is negatively correlated with } \\
& \alpha_{m}
\end{aligned}
$$

Proof:

$$
\begin{aligned}
& \frac{\partial m_{n}^{M F}}{\partial \alpha_{m}}=\frac{\partial m_{r}^{M F}}{\partial \alpha_{m}}=\frac{\partial w_{n}^{M F}}{\partial \alpha_{m}}=\frac{\partial p_{n}^{M F}}{\partial \alpha_{m}}=0, \\
& \frac{\partial w_{r}^{M F}}{\partial \alpha_{m}}=\frac{\partial p_{r}^{M F}}{\partial \alpha_{m}}=-\frac{\beta^{2}(1-\delta) \delta\left(\delta c_{n}-c_{r}\right)}{2\left(\beta^{2}-2(1-\delta) \delta \alpha_{m}\right)^{2}}<0 \\
& \frac{\partial q_{n}^{M F}}{\partial \alpha_{m}}=\frac{\beta^{2} \delta\left(\delta c_{n}-c_{r}\right)}{2\left(\beta^{2}-2(1-\delta) \delta \alpha_{m}\right)^{2}}>0, \frac{\partial q_{r}^{M F}}{\partial \alpha_{m}}=-\frac{\beta^{2} \delta\left(\delta c_{n}-c_{r}\right)}{2\left(\beta^{2}-2(1-\delta) \delta \alpha_{m}\right)^{2}}<0 \\
& \frac{\partial \pi_{\mathrm{m}}^{M F}}{\partial \alpha_{m}}=-\frac{\beta^{2}\left(\delta c_{n}-c_{r}\right)^{2}}{8\left(\beta^{2}-2(1-\delta) \delta \alpha_{m}\right)^{2}}<0, \frac{\partial \pi_{r}^{M F}}{\partial \alpha_{m}}=-\frac{\beta^{2}\left(\delta c_{n}-c_{r}\right)^{2}}{4\left(\beta^{2}-2(1-\delta) \delta \alpha_{m}\right)^{2}}<0 \\
& \frac{\partial \pi_{s c}^{M F}}{\partial \alpha_{m}}=-\frac{3 \beta^{2}\left(\delta c_{n}-c_{r}\right)^{2}}{8\left(\beta^{2}-2(1-\delta) \delta \alpha_{m}\right)^{2}}<0
\end{aligned}
$$

a) The price of new products and retailer's profit are not related to the guarantee cost coefficient of rework. This is because the extended warranty period of remanufactured product is the promotion proposed by manufacturer to stimulate sales of remanufactured product. As the retailer plays a leading role in this activity, the profit of $\mathrm{R}$ unit remanufactured product will not change, and prices of new products will not be affected.

b) The guarantee cost coefficient of remanufactured products will affect pricing, new products and sales volume of remanufactured products. That is, with the decrease of guarantee cost coefficient of remanufactured products, wholesale price, selling price, sales and guarantee period of remanufactured products will increase, while sales of new products will decrease, the overall profit of manufacturers, retailers and supply chain will increase. This is because as differentiated guarantee cost of rework decreases, manufacturer will extend the guarantee period of rework, which will stimulate consumers' willingness to pay, expand sales rework and increase selling price. At the same time, a higher selling price will tighten consumers' buying desire and reduce market demand for remanufactured products. However, for consumers, the influence of differentiated guarantee is greater than selling price, so the combined effect of two will increase sales and price of remanufactured products, while sales of new products will decrease. 


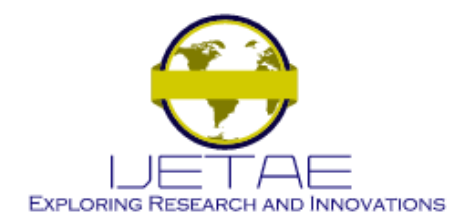

\section{International Journal of Emerging Technology and Advanced Engineering Website: www.ijetae.com (ISSN 2250-2459, ISO 9001:2008 Certified Journal, Volume 10, Issue 10, October 2020)}

c) Reducing the guarantee cost coefficient of remanufactured goods can improve the overall profit of manufacturers, retailers and supply chain. This is because: for $\mathrm{M}$, with the reduction of guarantee cost coefficient of remanufactured goods, unchanged pricing of new products and shrinking market, manufacturers' profits will shrink, but the reduction of guarantee cost of remanufactured goods, the increase of wholesale price and the expansion of remanufactured goods market will increase manufacturers' overall profits. Similarly, for the retailer, the profit of unit rework is unchanged, and the rework price is reduced and the guarantee period is extended, which makes the market expand, so the retailer's profit is gradually increased.

d)By comparing the sensitivity of differentiated guarantee period of consumers, it can be seen that the more sensitive consumers are, the faster the overall profit of manufacturers, retailers and supply chain will increase, and the higher the sensitivity is, the greater the profit gap between manufacturers and retailers will be. This is because extending the guarantee period of remanufactured products will bring profits to the sponsor manufacturers, and retailers, as the leading party of the supply chain, will regulate the sales volume and profit distribution of remanufactured products through the establishment of guarantee mechanism, so as to realize the "free rider" profit of this activity.

\section{Decision model under retailer guarantee mode $(R F)$}

$$
\begin{aligned}
& \pi_{m}^{M R}\left(w_{n}, w_{r}\right)=\left(w_{n}-c_{n}\right) q_{n}+\left(w_{r}-c_{r}\right) q_{r} \\
& \pi_{r}^{M R}\left(\mathrm{~m}_{n}, \mathrm{~m}_{r}, t_{r}\right)=\left(p_{n}-w_{n}\right) q_{n}+\left(p_{r}-w_{r}\right) q_{r}-\frac{\alpha_{r} \mathrm{t}^{2}}{2}
\end{aligned}
$$

By backward induction, the model has a unique optimal solution when $4 \delta \alpha_{r}(1-\delta)-\beta^{2}>0$. It can be obtained by solving the model:

$$
\begin{aligned}
& m_{\mathrm{n}}^{R F}=\frac{1-c_{n}}{2}, m_{r}^{R F}=\frac{\delta\left(1-c_{n}\right)}{2}+\frac{2\left(\delta c_{n}-c_{r}\right) \delta \alpha_{r}(1-\delta)}{4 \delta \alpha_{r}(1-\delta)-\beta^{2}}, \\
& t^{R F}=\frac{\beta\left(\delta c_{n}-c_{r}\right)}{4 \delta \alpha_{r}(1-\delta)-\beta^{2}}, \quad w_{\mathrm{n}}^{R F}=\frac{1+3 c_{n}}{4}, \\
& w_{r}^{R F}=c_{r}+\frac{\delta\left(1-c_{n}\right)}{4}+\frac{3\left(\delta c_{n}-c_{r}\right) \delta \alpha_{r}(1-\delta)}{4 \delta \alpha_{r}(1-\delta)-\beta^{2}} \\
& p_{\mathrm{n}}^{R F}=\frac{3+c_{n}}{4}, p_{r}^{R F}=c_{r}+\frac{3 \delta\left(1-c_{n}\right)}{4}+\frac{5(1-\delta) \delta \alpha_{r}\left(\delta c_{n}-c_{r}\right)}{4 \delta \alpha_{r}(1-\delta)-\beta^{2}} \\
& q_{\mathrm{n}}^{R F}=\frac{\left(1-c_{n}\right) \delta}{4}+\frac{\delta \alpha_{r}\left(\delta c_{n}-c_{r}\right)}{4 \delta \alpha_{r}(1-\delta)-\beta^{2}}, q_{r}^{R F}=\frac{-\alpha_{r}\left(\delta c_{n}-c_{r}\right)}{4 \delta \alpha_{r}(1-\delta)-\beta^{2}} \\
& \pi_{m}^{R F}=\frac{\left(1-c_{n}\right)^{2} \delta}{16}-\frac{3 \delta(1-\delta)\left(\delta c_{n}-c_{r}\right)^{2} \alpha_{r}^{2}}{\left(4 \delta(1-\delta) \alpha_{r}-\beta^{2}\right)^{2}} \\
& \pi_{r}^{R F}=\frac{\left(1-c_{n}\right)^{2} \delta}{8}-\frac{\left(\beta^{2}+4(1-\delta) \delta \alpha_{r}\right)\left(\delta c_{n}-c_{r}\right)^{2} \alpha_{r}}{2\left(4 \delta \alpha_{r}(1-\delta)-\beta^{2}\right)^{2}} \\
& \pi_{s c}^{R F}=\frac{3\left(1-c_{n}\right)^{2} \delta}{16}-\frac{\left(\beta^{2}+10(1-\delta) \delta \alpha_{r}\right)\left(\delta c_{n}-c_{r}\right)^{2} \alpha_{r}}{2\left(4 \delta \alpha_{r}(1-\delta)-\beta^{2}\right)^{2}}
\end{aligned}
$$

\section{Proposition 3:}

$$
\begin{aligned}
& m_{n}^{R F}, w_{n}^{R F}, p_{n}^{R F} \text { has nothing to do with } \alpha_{r} ; \\
& t^{R F}, q_{n}^{R F}, \pi_{\mathrm{m}}^{R F}, \pi_{\mathrm{r}}^{R F}, \pi_{s c}^{R F} \text { is positively correlated with } \alpha_{r} ; \\
& \mathrm{m}_{r}^{R F}, w_{r}^{R F}, p_{r}^{R F} q_{\mathrm{r}}^{R F} \text { is negatively correlated with } \alpha_{r} .
\end{aligned}
$$

Proof:

$$
\begin{aligned}
& \frac{\partial m_{n}^{R F}}{\partial \alpha_{r}}=\frac{\partial w_{n}^{R F}}{\partial \alpha_{r}}=\frac{\partial p_{n}^{R F}}{\partial \alpha_{r}}=0, \frac{\partial t^{R F}}{\partial \alpha_{r}}=\frac{\left(\delta c_{n}-c_{r}\right)\left(\beta^{2}+4(1-\delta) \delta \alpha_{r}\right)}{\left(\beta^{2}-4 \delta \alpha_{r}(1-\delta)\right)^{2}}>0 \\
& \frac{\partial m_{r}^{R F}}{\partial \alpha_{r}}=-\frac{2 \beta^{2}(1-\delta) \delta\left(\delta c_{n}-c_{r}\right)}{\left(\beta^{2}-4 \delta \alpha_{r}(1-\delta)\right)^{2}}<0, \frac{\partial w_{r}^{R F}}{\partial \alpha_{r}}=-\frac{3 \beta^{2}(1-\delta) \delta\left(\delta c_{n}-c_{r}\right)}{\left(\beta^{2}-4 \delta \alpha_{r}(1-\delta)\right)^{2}}<0 \\
& \frac{\partial p_{r}^{R F}}{\partial \alpha_{r}}=-\frac{5 \beta^{2} \delta \alpha_{r}\left(\delta c_{n}-c_{r}\right)}{\left(\beta^{2}-4 \delta \alpha_{r}(1-\delta)\right)^{2}}<0, \frac{\partial q_{r}^{R F}}{\partial \alpha_{r}}=\frac{\beta^{2}\left(\delta c_{n}-c_{r}\right)}{\left(\beta^{2}-4 \delta \alpha_{r}(1-\delta)\right)^{2}}<0 \\
& \frac{\partial q_{n}^{R F}}{\partial \alpha_{r}}=-\frac{\beta^{2} \delta\left(\delta c_{n}-c_{r}\right)}{\left(\beta^{2}-4 \delta \alpha_{r}(1-\delta)\right)^{2}}>0, \frac{\partial \pi_{m}^{R F}}{\partial \alpha_{r}}=\frac{6 \beta^{2}(1-\delta) \delta\left(\delta c_{n}-c_{r}\right)^{2} \alpha_{r}}{\left(4(1-\delta) \delta \alpha_{r}-\beta^{2}\right)^{3}}>0 \\
& \frac{\partial \pi_{r}^{R F}}{\partial \alpha_{r}}=\frac{\beta^{2}\left(\delta c_{n}-c_{r}\right)^{2} \alpha_{r}\left(12(1-\delta) \delta \alpha_{r}+\beta^{2}\right)}{2\left(4(1-\delta) \delta \alpha_{r}-\beta^{2}\right)^{3}}>0, \\
& \frac{\partial \pi_{s c}^{R F}}{\partial \alpha_{r}}=\frac{\beta^{2}\left(\delta c_{n}-c_{r}\right)^{2} \alpha_{r}\left(24(1-\delta) \delta \alpha_{r}+\beta^{2}\right)}{\left(4(1-\delta) \delta \alpha_{r}-\beta^{2}\right)^{3}}>0
\end{aligned}
$$

a) Regardless of the guarantee cost of remanufactured product, price of new product is not affected, while the guarantee period and price of remanufactured product are all increased with reduction of differentiated guarantee cost of remanufactured product. This is because with the decrease of guarantee cost coefficient of remanufactured goods, the guarantee cost will gradually decrease, and the longer the guarantee period of remanufactured goods will be, the longer the guarantee period will be, which will stimulate consumers' willingness to pay for remanufactured goods and improve various pricing of remanufactured goods. The retailer, as the organizer of the event, will increase the profit of rework unit. At the same time, with the increase in price of remanufactured products and the increase in consumers' willingness to pay, manufacturers are encouraged to increase wholesale price per unit of remanufactured products.

b) With the decrease of guarantee cost coefficient of remanufactured products, sales of new products increases and sales of remanufactured products decreases. This is because, with the reduction of cost coefficient of remanufactured products, retailers take the initiative to extend the guarantee period, prices of remanufactured products increase, and consumers' willingness to pay increases. However, price has less impact on sales of remanufactured products than the extension of guarantee period, which makes remanufactured products market shrink and new product market expand. 


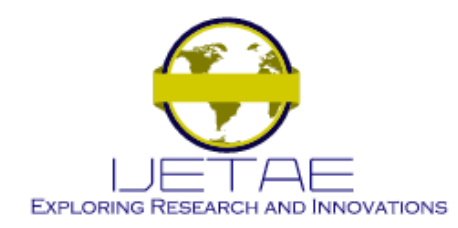

\section{International Journal of Emerging Technology and Advanced Engineering Website: www.ijetae.com (ISSN 2250-2459, ISO 9001:2008 Certified Journal, Volume 10, Issue 10, October 2020)}

c) With the decrease of the guarantee cost coefficient of remanufactured goods, the overall profits of manufacturers, retailers and supply chains are all increased. This is because the lower the guarantee cost coefficient, the longer the guarantee period, the higher the willingness of consumers to pay, and the larger the overall market capacity. As the sponsor of the guarantee activity and the leading party of the supply chain, to ensure the effect of the guarantee activity, we will formulate the price and coordinate the reasonable profit distribution to realize the coordination of supply chain.

d) The comparison of consumer sensitivities shows that as consumer sensitivities increase, manufacturers' profits rise, while retailers' and the supply chain's overall profits decline. This is because: the more sensitive the consumer is, the longer the guarantee period is, the stronger the "free-rider" profit-making behavior of the manufacturer is, and then the incentive of the retailer to extend the guarantee is reduced, and the overall profit decline of supply chain is accelerated.

\section{D.4.4 Comparison of equilibrium solutions of different guarantee models}

\section{Proposition 4:}

Comparison of decision-making variables and supply chain profits under different modes:

$$
\begin{aligned}
& m_{n}^{N F}=m_{n}^{M F}=m_{n}^{R F}, w_{n}^{N F}=w_{n}^{M F}=w_{n}^{R F}, p_{n}^{N F}=p_{n}^{M F}=p_{n}^{R F} ; \\
& m_{r}^{N F}=m_{r}^{M F}<m_{r}^{R F} ; w_{r}^{N F}>w_{\mathrm{r}}^{M F}, w_{r}^{N F}>w_{r}^{R F} ; p_{r}^{N F}<p_{\mathrm{r}}^{M F}, p_{r}^{N F}<p_{r}^{R F} ; \\
& \mathrm{t}_{r}^{R F}<t_{\mathrm{r}}^{M F}, q_{r}^{M F}>q_{r}^{N F}>q_{r}^{R F}, q_{n}^{R F}>q_{n}^{N F}>q_{n}^{M F} ; \\
& \pi_{\mathrm{m}}^{M F}>\pi_{m}^{N R}>\pi_{\mathrm{m}}^{R F} ; \pi_{r}^{M F}>\pi_{r}^{N R}>\pi_{r}^{R F} ; \pi_{s c}^{M F}>\pi_{s c}^{N R}>\pi_{s c}^{R F}
\end{aligned}
$$

Proof:

$$
\begin{aligned}
\mathrm{t}_{r}^{R F}-t_{r}^{M F} & =\frac{\left(-4 \delta\left(\alpha_{m}-\alpha_{r}\right)(1-\delta)-\beta^{2}\right) \beta\left(\delta c_{n}-c_{r}\right)}{\left(4 \delta \alpha_{m}(1-\delta)-2 \beta^{2}\right)\left(4 \delta \alpha_{r}(1-\delta)-\beta^{2}\right)}<0, m_{r}^{R F}-m_{r}^{M F}=\frac{2\left(\delta c_{n}-c_{r}\right) \delta \alpha_{r}(1-\delta)}{4 \delta \alpha_{r}(1-\delta)-\beta^{2}}>0 \\
w_{r}^{M F}-w_{r}^{N F} & =\frac{\beta^{2}\left(\delta c_{n}-c_{r}\right)}{4\left(2 \delta \alpha_{m}(1-\delta)-\beta^{2}\right)}>0, w_{r}^{R F}-w_{r}^{N F}=\frac{\left(\delta c_{n}-c_{r}\right)\left(\beta^{2}+8(1-\delta) \delta \alpha_{r}\right)}{4\left(4 \delta \alpha_{r}(1-\delta)-\beta^{2}\right)}>0 \\
p_{r}^{M F}-p_{r}^{N F} & =\frac{\beta^{2}\left(\delta c_{n}-c_{r}\right)}{4\left(2(1-\delta) \delta \alpha_{m}-\beta^{2}\right)}>0, p_{r}^{R F}-p_{r}^{N F}=\frac{\left(\delta c_{n}-c_{r}\right)\left(3 \beta^{2}+8(1-\delta) \delta \alpha_{r}\right)}{4\left(4 \delta \alpha_{r}(1-\delta)-\beta^{2}\right)}>0 \\
q_{n}^{M F}-q_{n}^{N F} & =-\frac{\beta^{2}\left(\delta c_{n}-c_{r}\right)}{4(1-\delta)\left(2(1-\delta) \delta \alpha_{m}-\beta^{2}\right)}<0, \quad q_{n}^{R F}-q_{n}^{N F}=\frac{\left(8 \delta \alpha_{r}(1-\delta)-\beta^{2}\right)\left(\delta c_{n}-c_{r}\right)}{4(1-\delta)\left(4 \delta \alpha_{r}(1-\delta)-\beta^{2}\right)}>0 \\
q_{r}^{M F}-q_{r}^{N F} & =\frac{\beta^{2}\left(\delta c_{n}-c_{r}\right)}{4(1-\delta) \delta\left(2(1-\delta) \delta \alpha_{m}-\beta^{2}\right)}>0, \quad q_{r}^{R F}-q_{r}^{N F}=-\frac{\left(8 \delta \alpha_{r}(1-\delta)-\beta^{2}\right)\left(\delta c_{n}-c_{r}\right)}{4(1-\delta) \delta\left(4 \delta \alpha_{r}(1-\delta)-\beta^{2}\right)}<0
\end{aligned}
$$

$$
\begin{aligned}
& \pi_{m}^{R F}-\pi_{m}^{N R}= \\
& -\frac{(1-\delta)\left(1-2 c_{n}\right)}{16}-\frac{\delta(1-\delta)^{2} c_{n}^{2}+\left(\delta c_{n}-c_{r}\right)^{2}}{16(1-\delta) \delta}-\frac{3(1-\delta) \delta\left(\delta c_{n}-c_{r}\right)^{2} \alpha_{r}^{2}}{\left(4 \delta \alpha_{r}(1-\delta)-\beta^{2}\right)^{2}}<0 \\
& \pi_{\mathrm{m}}^{M F}-\pi_{m}^{N R}= \\
& \frac{\left(1-c_{n}\right)^{2}}{16}+\frac{\left(\delta c_{n}-c_{r}\right)^{2}\left(2 \delta \alpha_{m}(1-\delta)+\beta^{2}\right)}{(1-\delta) \delta\left(2 \delta \alpha_{m}(1-\delta)-\beta^{2}\right)}>0 \\
& \pi_{r}^{R F}-\pi_{r}^{N R}= \\
& -\frac{\left(1-2 c_{n}\right)(1-\delta)}{8}-\frac{\delta(1-\delta)^{2} c_{n}^{2}+\left(\delta c_{n}-c_{r}\right)^{2}}{8(1-\delta) \delta}-\frac{\left(\delta c_{n}-c_{r}\right)^{2} \alpha_{r}\left(4 \delta \alpha_{r}(1-\delta)+\beta^{2}\right)}{2\left(4 \delta \alpha_{r}(1-\delta)-\beta^{2}\right)^{2}}<0 \\
& \pi_{r}^{M F}-\pi_{r}^{N R}=\frac{\beta^{2}\left(\delta c_{n}-c_{r}\right)^{2}}{8(1-\delta) \delta\left(2 \delta \alpha_{m}(1-\delta)-\beta^{2}\right)}>0, \\
& \pi_{\mathrm{sc}}^{M F}-\pi_{s c}^{N R}=\frac{3 \beta^{2}\left(\delta c_{n}-c_{r}\right)^{2}}{16(1-\delta) \delta\left(2 \delta \alpha_{m}(1-\delta)-\beta^{2}\right)}>0 \\
& \pi_{s c}^{R F}-\pi_{s c}^{N R}= \\
& -\frac{3\left(1-2 c_{n}\right)(1-\delta)}{16}-\frac{3 \delta(1-\delta)^{2} c_{n}^{2}+3\left(\delta c_{n}-c_{r}\right)^{2}}{16(1-\delta) \delta}-\frac{\left(\delta c_{n}-c_{r}\right)^{2} \alpha_{r}\left(10 \delta \alpha_{r}(1-\delta)+\beta^{2}\right)}{2\left(4 \delta \alpha_{r}(1-\delta)-\beta^{2}\right)^{2}}<0
\end{aligned}
$$

e) New product pricing, all models equal. The overall profit of $\mathrm{M}, \mathrm{R}$ and supply chain under different modes is higher than that of the unsecured mode.

f) Better sales of remanufactured products under the manufacturer guarantee mode.

g) From the perspective of member benefits and extended guarantee period, the manufacturer guarantee mode is the common choice of Mand R.

\section{ANALYSIS OF EXAMPLES}

The above theoretical analysis has drawn a general conclusion. In order to more visually and specifically show the influence of the sharing mode on each member of retailer-led closed-loop supply chain. A specific example is given below: $c_{n}=0.5, c_{r}=0.27, \delta=0.6, \quad \alpha_{m}=0.6$, and taking $\alpha_{r}$ as an independent variable, the decision variables under the three guarantee modes are compared. The results are shown in the figure, where $\beta$ is set at 0.1 and 0.5 respectively.

(1) The influence of guarantee cost parameters of two members on the guarantee period and sales price of remanufactured product

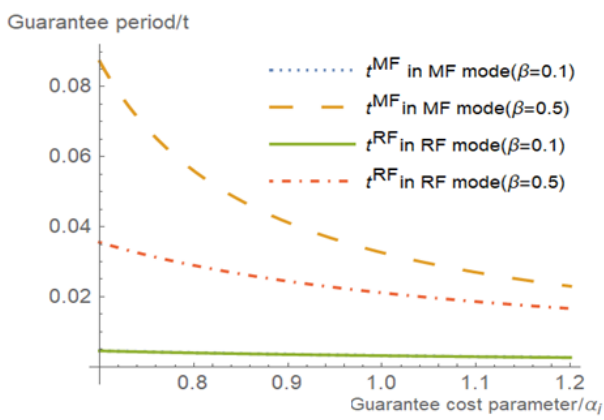

Fig.1 The influence of guarantee cost parameter on guarantee period of remanufactured goods 


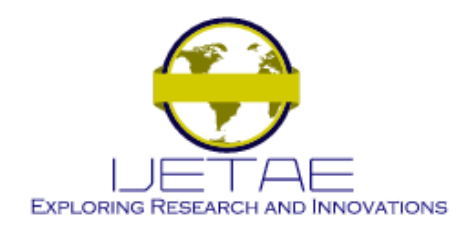

\section{International Journal of Emerging Technology and Advanced Engineering Website: www.ijetae.com (ISSN 2250-2459, ISO 9001:2008 Certified Journal, Volume 10, Issue 10, October 2020)}

It can be seen from Figure 1:

a) when consumers have low sensitivity to differentiated guarantee period of remanufactured products, whether to extend guarantee period or not, the level of guarantee cost coefficient is not a consideration.

b) When consumers are highly sensitive to differentiated guarantee period of remanufactured products, guarantee period of remanufactured products under two guarantee modes will gradually shorten with the increase of guarantee cost coefficient. Moreover, compared with the manufacturer's guarantee cost coefficient, the retailer's guarantee cost coefficient has more significant influence on the extension or shortening of guarantee period.

c) The higher the consumer sensitivity is, the longer the guarantee period will be.

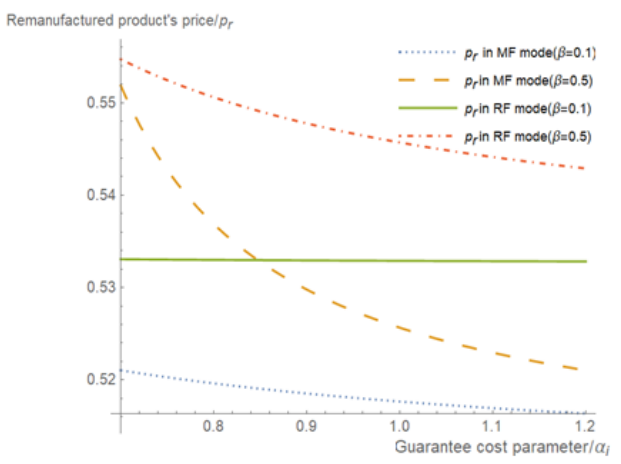

Fig.2 The influence of guarantee cost parameter on the price of remanufactured goods

It can be seen from figure 2:

a) When consumers are less sensitive to the differentiated guarantee period of remanufactured products, the guarantee cost under the two guarantee modes basically does not affect the selling price and guarantee cost of remanufactured products.

b) The price of remanufactured products under manufacturer guarantee mode is lower than that under retailer guarantee mode.

c) When consumers are sensitive to differentiated guarantee period of remanufactured products, with the increase of guarantee cost, price of remanufactured products will decrease greatly, and price reduction of manufacturer's guarantee mode is particularly obvious.

(2) The influence of guarantee cost parameters of two members on sales of new products and remanufactured products

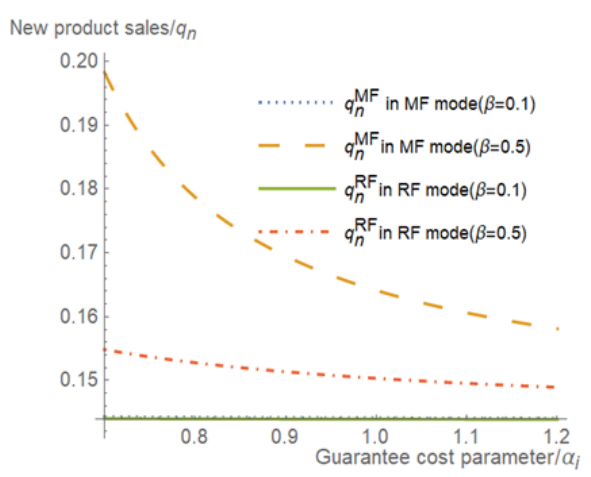

Fig.3 The influence of guarantee cost parameters on new product sales

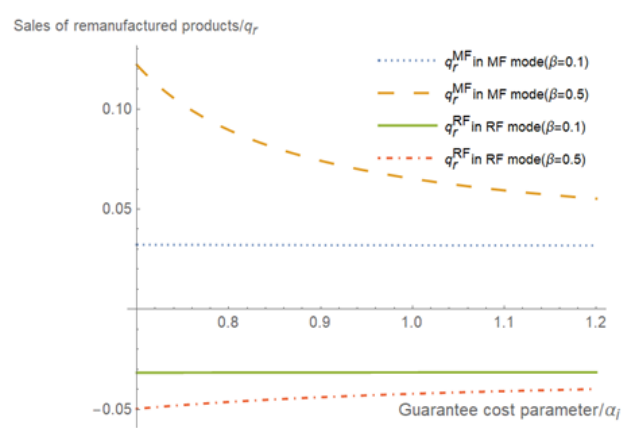

Fig.4 The influence of guarantee cost parameter on rework sales volume

Figure 3 and 4 show that:

a) When consumers have low sensitivity to differentiated guarantee period, with the increase of guarantee cost coefficient, the sales volume of new products and remanufactured products remain basically unchanged. When consumers have a high sensitivity to the differentiated guarantee period, under the manufacturer guarantee mode, with the increase of guarantee cost coefficient, the sales of remanufactured products declines rapidly, while sales of new products increases, which is the result of destructive effect of new product market on remanufactured product market.

b) Under MF and RF, the sales of new products with low sensitivity are higher than those with low sensitivity, while the sales of remanufactured products are just the opposite. This is because when the consumer sensitivity is high, the guarantor will take the initiative to extend the guarantee period to stimulate the consumption of remanufactured products, which results in the transfer of consumers from new product market to remanufactured product market. 


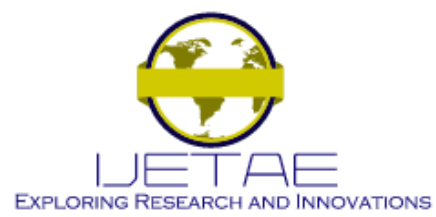

\section{International Journal of Emerging Technology and Advanced Engineering Website: www.ijetae.com (ISSN 2250-2459, ISO 9001:2008 Certified Journal, Volume 10, Issue 10, October 2020)}

c) Under RF, the sales of remanufactured products is 0 , and sales of new products is higher than the manufacturer's guarantee mode. The higher the consumer sensitivity is, the higher the sales of new products will be. MF's new product sales were lower than RF, while the remanufactured product sales of $\mathrm{MF}$ mode were higher than RF mode.

(3)The impact of the two member guarantee cost parameters on the profits of the manufacturer, retailer and supply chain

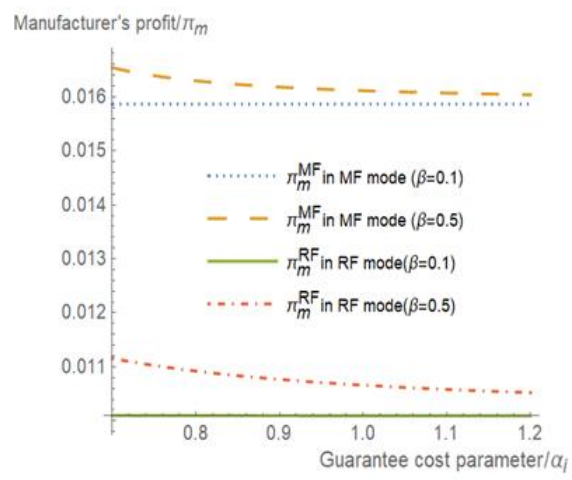

Fig.5 The influence of guarantee cost parameter on manufacturer's profit

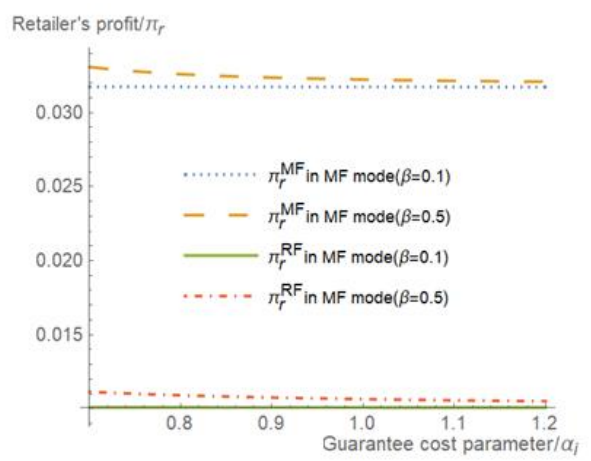

Fig.6 The influence of guarantee cost parameter on retailer's profit

By comparing figure 5 and figure 6 , it can be seen that :

a) When the consumer sensitivity is low, profits of manufacturers and retailers are basically unchanged with different guarantee cost parameters. However, under the same guarantee cost parameter, the higher the consumer sensitivity is, the higher the profit of manufacturer or retailer will be. b) When the consumer sensitivity is high, with the increase of guarantee cost parameters, the profit of both manufacturers and retailers decreases, and the profit of the guarantor decreases more obviously.

c) Under each guarantee mode, the profit of manufacturers and retailers is greater than 0 , and under the same guarantee cost coefficient, the profit of manufacturers and retailers under the guarantee mode is the highest.

d) when the consumer sensitivity is low, SC profit is basically unchanged as the guarantee cost parameter increases. The higher the consumer sensitivity is, the higher SC profit will be.

e) When consumer sensitivity is high, SC profit decreases with the increase of guarantee cost parameter, and SC profit decreases more obviously under MF.

f) The SC profit under each guarantee mode is greater than 0 , and the SC profit under MF is better than RF.

\section{CONCLUSION}

Based on the retailer leading closed-loop supply chain and product differentiation of service guarantee period as the research object, build no secured party, manufacturers guarantee, retailers guarantee three game models, and focus on examination of consumers to product differentiation guarantee period sensitivity, and product differentiation guarantee cost high and low impact on members of CLSC decision-making and earnings. Through model comparison and analysis, the following conclusions can be drawn :(1) when consumers have low sensitivity to differentiated guarantee period, CLSC decision variables such as guarantee period, re-product selling price, product sales volume, members and overall profits of supply chain are basically unrelated to guarantee mode and guarantee cost parameters. (2) When consumers have a high sensitivity to differentiated guarantee period, under the same guarantee cost coefficient, the advantages of retailer guarantee mode are reflected in longer guarantee period, higher prices of remanufactured products and higher sales of new products. However, the advantages of manufacturer guarantee mode are reflected in higher sales of remanufactured products and higher profits of the whole supply chain. At the same time, with increasing of guarantee cost parameters, all decision-making variables and overall profits of supply chain are declined. (3) The guarantee mode is beneficial to extending the guarantee period, reducing the price of remanufactured products, and improving the overall profit of supply chain. 


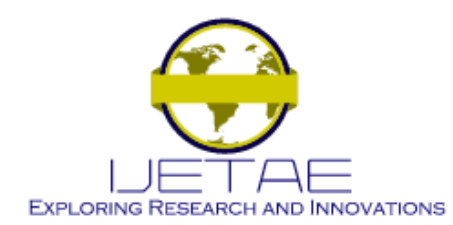

\section{International Journal of Emerging Technology and Advanced Engineering Website: www.ijetae.com (ISSN 2250-2459, ISO 9001:2008 Certified Journal, Volume 10, Issue 10, October 2020)}

This paper compared different guarantee mode retailer leading closed-loop supply chain members of the decisionmaking, discusses the choice of the secured party, the cost of insuring parameters affect the retailer leading closedloop supply chain and profit, the model does not consider subsidies, such as corporate social responsibility consciousness of the members and the influence of product differentiation guarantee decision-making, and did not consider product recycled closed-loop supply chain decisions for members to guarantee product differentiation, the effect of this is the direction of further research.

\section{REFERENCES}

[1] G. Esenduran, E. K. Ziya, J. M. Swaminathan. Take-back legislation: Consequence for remanufacturing and environment. Decision Sciences, 2016, 47(2): 219-256.

[2] Y. Dal, S. X. Zhou, Y. F. Xu. Competitive and Collaborative quality and warranty management in supply chains. Production and Operations Management, 2012, 21(1): 129-144.

[3] E. Galor . Warranties as a signal of quality. Canadian Journal of Economics, 1989, 22(1): 50-61.

[4] G. A. Decroix. Optimal warranties reliabilities and prices for durable goods in an oligopoly. European Journal of Operational Rearch,1999, (12): 544-669.

[5] S. Balachander. Warranty signaling and reputation. Management Science, 2001, 47(9): 1282-1289.

[6] M. Spence. Consumer misperceptions, product failure and producer liability. Review of Economic Studies,1977,(44): 561-572

[7] Shimp, Terence, A, et al. Warranty and Other Extrinsic Cue Effects on Consumers' Risk Perceptions[J]. Journal of Consumer Research,1982,9: 38-46.

[8] S. J. Tan, K. S. Lee, G. H. Lim. Warranty and warrantor reputations as signals of hybrid product quality. European Journal of Marketing, 2001, 35 (1/2): 110-132.
[9] B. F. Liao. Warranty as a Competitive Dimension for Remanufactured Products under Stochastic Demand. Journal of Cleaner Production, 2018, 198: 511-519.

[10] N. Li, Y. L. Li. Closed-loop Supply chain Coordination Strategy based on Product Guarantee Period. Systems Engineering, 2016, 34(7): 90-96.

[11] S. M. H. Motlagh, M. Nematollahi, M. Nouri. Coordination of green quality and green warranty decisions in a two- echelon competitive supply chain with substitutable products. Journal of Cleaner Production, 2018, 196: 961-984.

[12] B. F. Liao, B. Y. Li, Z. Liu. Guarantee operation efficiency of remanufactured products. Journal of systems management,2019,28(4):783-7890.

[13] B. F. Liao, B. Y. Li, X. P. Ma, Y. Zhou. Guarantee Decision Model of closed-loop Supply chain System. Systems Engineering, 2012,36(2):141-145.

[14] N. Li, B. Y. Li, Z. Liu. Research on guarantee subject and guarantee efficiency of remanufactured products. Operations research and management, 2016, 25 (5): 249-257.

[15] S. A. Yazdian, K. Shahanaghi, A. Makui. Joint optimization of price, warranty and recovery planning in remanufacturing of used products under linear and non-linear demand, return and cost functions. International journal of systems Science, 2014, 47(5-8):1155-1175.

[16] A. Y. Alqahtani, S. M. Gupta. Warranty a as a Marketing Strategy for Remanufactured Products. Journal of Cleaner Production, 2017, 161: 1294-1307.

[17] X. P. Ma, Z. Liu, B. Y. Li, J. Tang, X. X. Zheng. Research on closed-loop Supply chain Game Model considering retailers' Equity Concerns under different guarantee Modes. Control and decision making. https://doi.org/10.13195/j.kzyjc.2019.1328.

[18] Q. H. Zhu, H. L. Li, S. L. Zhao, V. Lun. Redesign of Service Modes for Remanufactured Products and Its Financial Benefits. International Journal of Production Economics,2016, 171:231-240.

[19] K. P. Li, S. Mallik, D. Chhajed. Design of extended warranties in supply chains under additive demand. Production and Operations Management, 2012, 21(4): 730-746. 